\title{
Experimental Study on Spine Segment Fixation Technique
}

\author{
Gediminas LUKŠYS*, Kristina DAUNORAVIČIENË**, Julius GRIŠKEVIČIUS***, \\ Mindaugas RIMAITIS****, Rimantas STONKUS*****, Gunaras TERBETAS $* * * * * *$ \\ *Vilnius University, Universiteto str. 3, LT-01513 Vilnius, Lithuania, E-mail: gedimin.luksys@ gmail.com \\ **Vilnius Gediminas Technical University, J. Basanavičius str. 28, LT-03224 Vilnius, Lithuania, \\ E-mail: kristina.daunoraviciene@vgtu.lt \\ ***Vilnius Gediminas Technical University, J. Basanavičius str. 28, LT-03224 Vilnius, Lithuania, \\ E-mail: julius.griskevicius@vgtu.lt \\ ****Vilnius Gediminas Technical University, J. Basanavičius str. 28, LT-03224 Vilnius, Lithuania, \\ E-mail: mindaugas.rimaitis@gmail.com \\ *****Vilnius Gediminas Technical University, J. Basanavičius str. 28, LT-03224 Vilnius, Lithuania, \\ E-mail: rimantas.stonkus@vgtu.lt \\ ******Vilnius University, Universiteto str. 3,LT-01513 Vilnius, Lithuania, E-mail: gunaras.terbetas@mf.vu.lt \\ cross $^{\text {ref }}$ http://dx.doi.org/10.5755/j01.mech.24.2.19226
}

\section{Introduction}

Since the introduction in early 90's [1] spinal instrumented fusion techniques evolved numerously and became routinely used in all spinal units [2] and has become a standard of care for numerous pathological conditions of the human spine. The most popular surgical method is transpedicular screw fixation when screws are inserted into vertebras via transpedicular access, connected with rods and fixed rigidly. Motion segment of the spine becomes immobile, allowing adequate decompression of neural structures and achieving bony fusion later. Instrumented fusion is being used for conditions such as trauma, low back pain, spinal stenosis and degenerative spondylolisthesis [3]. Over the last decade the number of instrumented fusion surgeries increased more than 15 times [2]. With increased amounts of patients operated and prolonged years of follow up, delayed spinal problems occur. Introduction of completely rigid segment into moving spine gives additional stress to adjacent spinal segments not involved in fixation. After distant time these segments sustain faster degeneration of facet joins and intervertebral discs. The condition can be determined radiologically and present with new onset of symptoms and is called adjacent segment disease (ASD) [4]. The radiographic ASD is defined as radiographical changes seen at levels adjacent to a previous spinal fusion procedure that do not correlate with any clinical findings; whereas symptomatic ASD referred to the development of new clinical symptoms that correspond to radiographical changes adjacent to the level of a previous spinal fusion [4]. The radiographic ASD may develop to the symptomatic ASD, and the symptomatic ASD will lead to pain, dysfunction, or even need for additional spine surgery [5]. From 1996 to 2012, 51 studies for lumbar ASD were published, radiographic ASD prevalence is $26.6 \%$ and symptomatic ASD prevalence is $8.5 \%$ [4]. It's shown that one fifth to one third of the patients with radiographical ASD will develop clinically symptomatic ASD. With such a common prevalence in follow-up studies, adjacent segment disease becomes one of the most restrictive factors in decision for instrumented fusion surgery.

Previous studies have shown, that there are statistically significant factors like genetics; age; length of the rigidly fixed spinal segment, which increase the probability of a patient to relapse after initial surgery [6]. The exact mechanism of the ASD is not yet fully understood. But most investigators think that increase in neighboring discs' pressure [7] and increase in von Mises stress, the Tresca stress of annulus fibrosus of adjacent to the fusion level [8] creates additional load on facet joints and intervertebral discs, causing faster degeneration eventually. Chow et al. [9] identified that the mobility of the motion segments immediately above and below an L4-L5 fusion was increased in flexion, so not only additional load but also the direction of loading is important. These changes may be an important reason for postoperative ASD.

Scientists accept using spines obtained from animals for in vitro testing as an option to replace specimens from post-mortem human subjects (PMHS), because it is easier to get more samples with similar geometric and physiological parameters. Sheng [10], after a full scientific articles review, wrote that spines of the most of the large animals, such as pigs, sheep, goats, dogs, as models are suitable for use in spinal research. Research works of Büsscher [11] and Sheng [10] have confirmed that the porcine lumbar spinal sample compared with other animal samples are superior as an analogue for PMHS spines. The studies used to test objects are cadaveric [12-16] or animal [17, 18].

A new approach to single spine segment fixation was tested during this study. This study is focused on the analysis of single spine segment fixation using monoaxial screws, straight and bended rods. The main objectives are to identify how biomechanical properties of whole spine and especially motion segments, neighboring fixed segment, change with applying axial loading, flexion and extension loading forces. We hypothesize that single segment fixation by screws and rods would have a negative impact on spine biomechanical properties. We aim to determine which direction of loading would have the most significant impact on movement and potentially most hazardous effect on adjacent segments. We aim to determine how bending the rod may influence or diminish this hazardous effect.

\section{Methods}

Experimental studies were carried out in the labo- 
ratory of Vilnius Gediminas Technical University, in collaboration with scientists and clinicians from the Republican Vilnius University Hospital. For in vitro testing 7 porcine lumbar spines each consisting of 4 vertebras have been used. Each spine sample has been tested unfixed and then rigidly fixed. All spinal samples were divided according their fusion into groups: $\mathrm{CO}$ - unfixed controls, FSR - one segment fused by screws and straight rod (Fig. 1, a), FBR - one segment fixed by screws and the rod bent by $15^{\circ} \pm 0.5$ angle
(Fig. 1, b). During the fixation the middle spinal segment was consolidated by four $50 \mathrm{~mm}$ long, $6.5 \mathrm{~mm}$ diameter titanium monoaxial screws and four $80 \mathrm{~mm}$ long, $5 \mathrm{~mm}$ diameter titanium rods (two straight and two bent). Total 9 tests were conducted for each spinal sample. Three different load tests to simulate the flexion, extension and axial loading were carried out for CO, FSR and FBR groups.

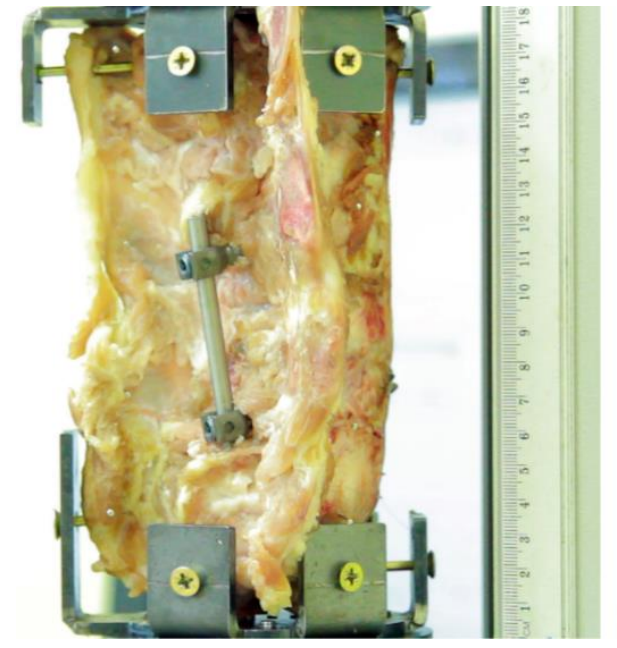

a

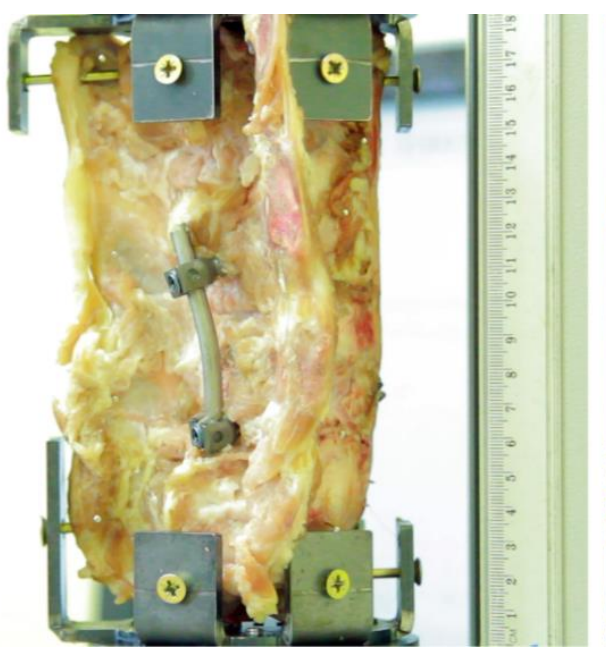

b

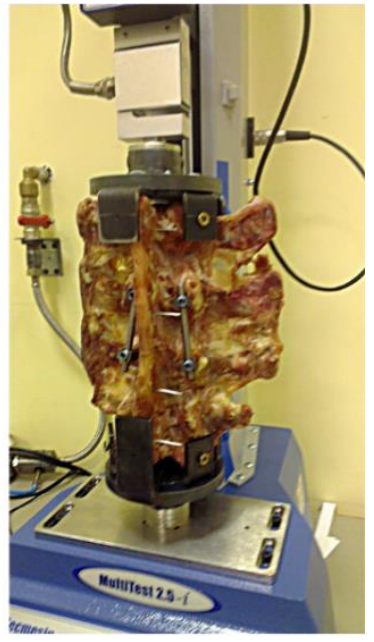

Fig. 1 Spinal segment fixation techniques: a) vertebral segment, fixed with monoaxial screws and straight rod; b) vertebral segment, fixed with monoaxial screws and bent rod; c) L2-L5 spinal segment (FSR) prepared for a test

The computer-controlled tension-compression test system "Mecmesin Multitesters 2.5-i" (Mecmesin Limited, United Kingdom, maximum load: $2500 \mathrm{~N}$; maximum sample diameter: $134 \mathrm{~mm}$; load sensor measurement error: \pm $0.1 \%$; speed range: $1-1000 \mathrm{~mm} / \mathrm{min}$ ) was used for the experiments. The force was measured using the $1000 \mathrm{~N}$ resolution load cell. The testing machine was controlled by the software "Emperor" (Mecmesin Limited, United Kingdom). Since testing stand is designed for axial tension-compression tests, it was necessary to create a system that could simulate the flexion/extension. Scientific analysis of the Skrzypiec spine mounting method was the closest to our necessities [12]. In order to utilize this method, the cup-shaped holder had to be modified. For fixing the spine segment in testing machine the holders were specially designed and manufactured. Bending simulation methodology has been drawn up in accordance with Karakasli study description [18]. Research metrics present flexion moments exerted on the spine range between $3 \mathrm{Nm}$ and $12 \mathrm{Nm}[12,18]$. Since current study aims to keep the spine intact during the test, the upper holder was adapted to create a bending moment of $2.4 \mathrm{Nm}$ close to the minimal limit of mentioned range of $3 \mathrm{Nm}$.

\section{Experimental protocol}

Seven sound porcine spinal segments, covering the L2-L5 vertebrae were carefully separated from the rest of the spine and stored at $-20^{\circ} \mathrm{C}$. The day before the examination spine specimens were thawed at room's temperature while maintaining appropriate moisture. Unnecessary excess soft tissues were removed from specimens preserving intact ligaments connecting the vertebrae, intervertebral joints and intervertebral disc structures. The samples were consolidated by fixing screws and performing $\mathrm{x}$-ray for checking if the spine has no physiological abnormalities, is not mechanically damaged and screws are positioned correctly (Fig. 2).
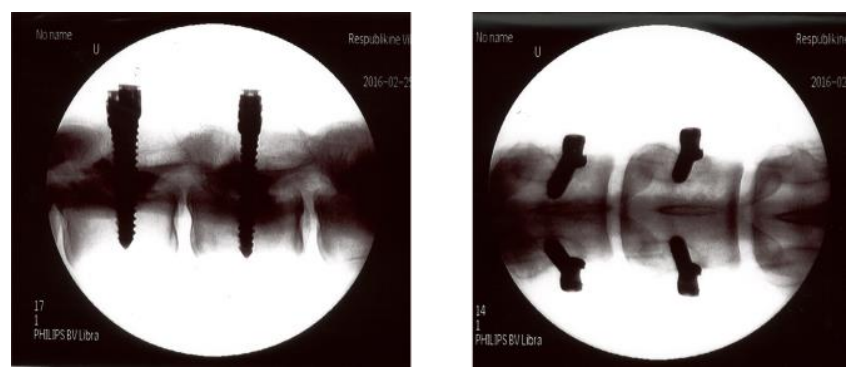

Fig. 2 X-ray of transpedicular screws in lateral (left) and anteroposterior (right) view

Holders were mechanically mounted on the L2 and L5 vertebral bodies by screws of $5 \mathrm{~mm}$ diameter to $80 \mathrm{~mm}$ long. After both (upper and lower) parts of a specimen were properly fitted into holders it was prepared for testing it in the stand (Fig. 1, c). Testing conditions: axial load $400 \mathrm{~N}$ was applied in all loading scenarios; bending moment $2.4 \pm$ $0.04 \mathrm{Nm}$, which was created by changing the position of the spine specimen with respect to loading column of a machine; $20 \mathrm{~mm} / \mathrm{min}$ speed (low-load selected speed); displacement dependence on the load ratio was fixed to 200 $\mathrm{Hz}$; Estimated load maintaining limit was $400 \mathrm{~N}$ in duration of 20 seconds. Knowing that during in vitro tests, the first two spinal tests are inaccurate [13], two precondition cycles were carried out for each spine specimen. Between precondition cycles 2 minutes' breaks were conducted for the spine 
to recover to its original state. During the third cycle, measurement data was recorded. Displacement data were recorded from the start (without any load) to the end of experiment (until maximal load of $400 \mathrm{~N}$ was exceeded).

\section{Data processing and analysis}

Load-displacement data was collected and pre-processed utilising EMPEROR software. Further analysis was performed using MATLAB (Mathworks, Sweden). Due to different sizes of the porcine samples, the measurement data was normalized to maximal value of $\mathrm{CO}$ for each loading case. A one-way repeated measures ANOVA with Tukey-

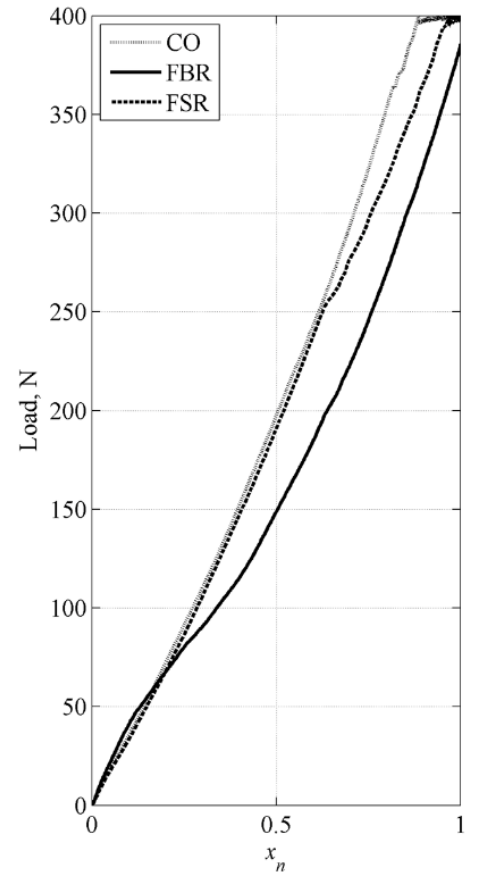

a

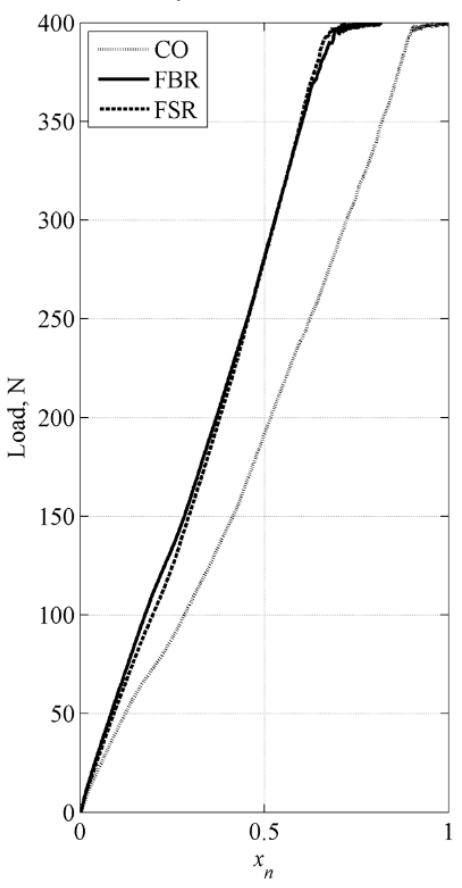

b
Kramer post-hoc analysis with a significance level of $\alpha=$ 0.05 was used to test the null hypothesis that the means of compared fixation methods groups are equal. The TukeyKramer minimum significant differences (MSD) were calculated for each group of the means.

\section{Results}

Load-displacement diagrams showing averaged displacement in each group are presented in Figure 3 and data of displacement are shown along all loading cases in the Table 1 .

Fig. 3 Normalized displacement due to loading size within the groups: a) axial loading; b) flexion; c) extension

Spine segment displacement data

Table 1

\begin{tabular}{|r|l|c|c|c|c|c|c|}
\hline \multirow{2}{*}{ No } & \multicolumn{1}{|c|}{ Test type } & \multicolumn{2}{|c|}{ Axial loading } & \multicolumn{2}{|c|}{ Flexion } & \multicolumn{2}{c|}{ Extension } \\
\cline { 2 - 8 } & \multicolumn{1}{|c|}{ Parameter } & $\begin{array}{c}x_{\text {avg }} \pm \mathrm{SD}, \\
\mathrm{mm}\end{array}$ & $\begin{array}{c}x_{\max } \pm \mathrm{SD}, \\
\mathrm{mm}\end{array}$ & $\begin{array}{c}x_{\text {avg }} \pm \mathrm{SD}, \\
\mathrm{mm}\end{array}$ & $\begin{array}{c}x_{\max } \pm \mathrm{SD}, \\
\mathrm{mm}\end{array}$ & $\begin{array}{c}x_{\text {avg }} \pm \mathrm{SD}, \\
\mathrm{mm}\end{array}$ & $\begin{array}{c}x_{\max } \pm \mathrm{SD}, \\
\mathrm{mm}\end{array}$ \\
\hline 1. & CO $(\mathrm{n}=6)$ & $1.70 \pm 0.44$ & $1.74 \pm 0.44$ & $1.69 \pm 0.53$ & $2.05 \pm 0.53$ & $1.47 \pm 0.43$ & $1.76 \pm 0.38$ \\
\hline 2. & FSR $(\mathrm{n}=6)$ & $1.53 \pm 0.46$ & $1.84 \pm 0.55$ & $1.32 \pm 0.36$ & $1.56 \pm 0.17$ & $1.55 \pm 0.47$ & $1.87 \pm 0.54$ \\
\hline 3. & FBR $(\mathrm{n}=6)$ & $1.64 \pm 0.51$ & $1.97 \pm 0.48$ & $1.34 \pm 0.37$ & $1.59 \pm 0.17$ & $1.64 \pm 0.51$ & $2.00 \pm 0.48$ \\
\hline
\end{tabular}

$x_{a v g}, x_{\max }-$ averaged and maximal deformation of the spine segment, SD - standard deviation.

Table 1 presents results from 6 spinal samples. During axial loading one the 7 specimens was damaged and since the spinal fluid leaked, it could no longer be used for the further experiments and results of this specimen were not evaluated. It can be noted, that the specimens exhibit nearly elastic behaviour until the maximum load of $400 \mathrm{~N}$ in all three loading scenarios (axial loading, flexion and extension). Displacement values (Fig. 3) under axial loading and extension test vary very little. A one-way repeated measures ANOVA analysis with a significance level of $\alpha=$ 0.05 revealed that there is no statistically significant effect of both fixation methods (FBR or FSR) on the displacement during an axial loading when comparing with unfixed spinal sample (Fig. 3), which means that both fixation methods might be used when fusing not more than two vertebrae or one motion segment.

In general, during the flexion test FBR and FSR causes lower deformation compared to unfixed case (Fig. 3), the spine becomes stiffer, while during the extension and axial loading the deformation is almost the same, which is proved by statistical analysis - no statistically significant differences found in maximum displacement values between three groups. The differences of maximum displacement values were statistically significant while comparing the axial loading and flexion when spine was fixed with FBR and FSR. 
Displacement variation over time along spinal fixation methods under different tests presented in the Fig. 4. Axial loading and extension causes less deformation in unfixed sample (CO) and more deformations appear in both FSR and FBR. However, comparing fixation methods it was noted that in FBR spine deforms faster and with higher magnitude. Obviously, different situation might be observed in flexion test. Fixed sample behaved in more stable way. Therefore, lower deformation was found as well as shorter deformation duration in both FSR and FSB fixation cases.

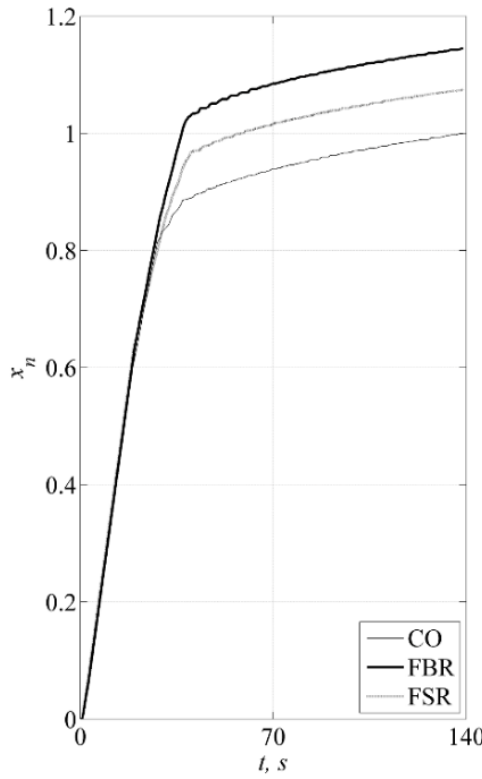

a

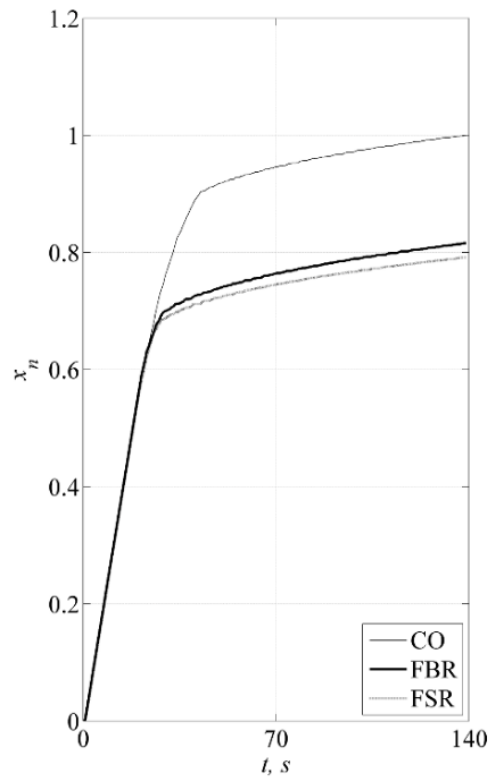

b

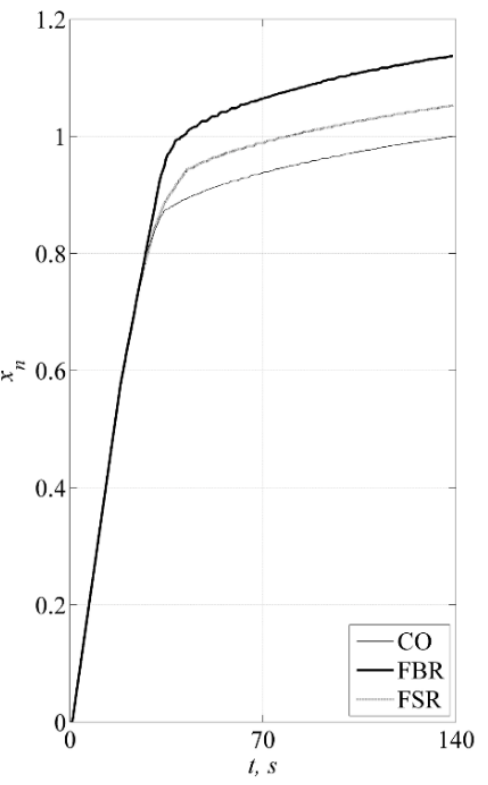

$\mathrm{c}$

Fig. 4 Normalized displacement vs loading time within the groups: a) axial loading; b) flexion; c) extension

Both fusion methods affect wear of spinal segments that is proved by larger deformations in spinal segments under axial testing and extension (Fig. 3). Lower capability for deformation under flexion means more wear of segments adjacent to rigid fixation. However, the deformation is increasing in the same cases as well (Fig. 4). Thus, both these facts can be contributing to ASD.

\section{Discussion}

Transpedicular fixation of spine remains one of the most effective treatment tools for numerous spine disorders, but adjacent segment disease becomes restrictive factor for application of this method.

The results of this study differ from the results of other scientists [12], [18] in extension testing. Karakaşl1 study obtained maximum displacement results for a healthy sheep spine comparing with a reinforced rigid decreased 1.4 $\mathrm{mm}$ during extension trials; $\leq 0,5 \mathrm{~mm}$ in flexion tests. While in our study axial loading presented increased deformations from 0,14 to $0,27 \mathrm{~mm}$, extension - from 0,09 to $0.14 \mathrm{~mm}$ and may have negative impact on adjacent segments in both fusion methods. However, flexion tests support above-mentioned results [18] and obtain from 0.49 to $0.54 \mathrm{~mm}$ less displacement in both FSR and FBR. Tukey-Kramer MSD differences in both spinal fixation methods and $\mathrm{CO}$ only in flexion test were found. The variance of our results may appear because in other scientific works firstly in vitro tests have been performed using appropriate cadaver and sheep spines segments, secondly, higher $(8.4 \mathrm{Nm})$ bending load was used, which could influence the results. Skrzypiec et al. the maximal load of $500 \mathrm{~N}$ was used [12]. Since we used the same spine sample for all testing cases, larger than $500 \mathrm{~N}$ loading may result in irreversible changes in object structure and affect its recovery options. Therefore, taking into ac- count our experiment conditions, $400 \mathrm{~N}$ loading limitation was set for the tests. Supervising our results, axial loading and extension causes less wear to adjacent segments than flexion, so fixing single spine segment diminishes flexion ability and flexion movement is potentially more hazardous for developing adjacent segment disease, we did not found differences in straight or bended rod fixation methods.

\section{Limitation of our study}

The study showed that a rigid fixation of the spine segment has a negative impact on adjacent segments biomechanics, especially evident in flexion movement, but the difference between straight and bended spinal fixation methods remains questionable. Porcine spine due to its unique curvature (lumbar kyphosis) is not suitable for determining exact rod bend angle and our data cannot be directly transferred to human spine conditions. We assume that our test limitations were too strict and ultimate stress might be higher in order to make deeper analysis with porcine spine specimens.

\section{Conclusions}

Experimental study proved to be valuable for biomechanical analysis of spine before and after applying single segment fixation. Statistical comparison of displacement results indicated significant differences only under flexion test and flexion movement is potentially most hazardous for developing adjacent segment disease. Obtained results confirmed that investigated fixation techniques with straight and bended rods did not differ in any case of loading and both techniques show no biomechanical differences in fusing single movement segment, but keeping in mind limitations of our study this data cannot be directly transferred to human spine conditions. All other results showed that fixa- 
tion methods of spine segment have no significant influence on axial loading and extension up to set load of $400 \mathrm{~N}$.

\section{References}

1. Boos, N.; Webb, J. K. 1997. Pedicle screw fixation in spinal disorders: A European view, European Spine Journal 6(1): 2-18.

https://dx.doi.org/10.1007\%2FBF01676569.

2. Deyo, R. A.; Mirza, S. K.; Martin, B. I.; Kreuter, W.; Goodman, D. C.; Jarvik, J. G. 2010. Trends, major medical complications, and charges associated with surgery for lumbar spinal stenosis in older adults, Jama 303 (13): 1259-1265. https://dx.doi.org/10.1001/jama.2010.338.

3. Matz, P. G. et al. 2016. Review Article : Guideline summary review : an evidence-based clinical guideline for the diagnosis and treatment of degenerative lumbar spondylolisthesis, Spine J. $16: 439-448$. https://dx.doi.org/10.1016/j.spinee.2015.11.055.

4. Xia, X.-P.; Chen, H.-L.; Cheng, H.-B. 2013. Prevalence of adjacent segment degeneration after spine surgery: a systematic review and meta-analysis, Spine 38(7): 597-608.

https://doi.org/10.1097/BRS.0b013e318273a2ea.

5. Jansson, K. Å.; Németh, G.; Granath, F.; Blomqvist, P. 2005. Spinal stenosis re-operation rate in Sweden is $11 \%$ at 10 years - A national analysis of 9,664 operations, European Spine Journal 14(7): 659-663. https://dx.doi.org/10.1007\%2Fs00586-004-0851-9.

6. Radcliff, K. E. et al. 2013, Adjacent segment disease in the lumbar spine following different treatment interventions, Spine J. 13(10): 1339-1349. https://doi.org/10.1016/j.spinee.2013.03.020.

7. Cunningham, B. W.; Kotani, Y.; McNulty, P. S.; Cappuccino, A.; McAfee, P. C. 1997. The effect of spinal destabilization and instrumentation on lumbar intradiscal pressure: an in vitro biomechanical analysis, Spine 22(22): 2655-2663.

https://doi.org/10.1097/00007632-199711150-00014.

8. Goto K, Tajima N, Chosa E. et al. 2003Effects of lumbar spinal fusion on the other lumbar intervertebral levels (three-dimensional finite element analysis). J. Orthop Sci 8:577-584. https://doi.org/10.1007/s00776-003-0675-1.

9. Chow, D. H. K.; Luk, K. D. K.; Evans, J. H.; Leong, J. C. Y. 1996. Effects of Short Anterior Lumbar Interbody Fusion on Biomechanics of Neighboring Unfused Segments, Spine (Phila. Pa. 1976) 21(5): 549-555. https://insights.ovid.com/pubmed?pmid=8852308. https://doi.org/10.1097/00007632-199603010-00004.

10. Sheng, S. R.; Wang, X. Y.; Xu, H. Z.; Zhu, G. Q.; Zhou, Y. F. 2010. Anatomy of large animal spines and its comparison to the human spine: A systematic review, European Spine Journal 19(1): 46-56. https://doi.org/10.1007/s00586-009-1192-5.

11. Busscher, I.; Ploegmakers, J. J. W.; Verkerke, G. J.; Veldhuizen, A. G. 2010. Comparative anatomical dimensions of the complete human and porcine spine, Eur. Spine J. 19(7): 1104-1114. https://doi.org/10.1007/s00586-010-1326-9.

12. Skrzypiec, D. M.; et al. 2012. Shear strength of the human lumbar spine, Clin. Biomech. 27(7): 646-651. https://doi.org/10.1016/j.clinbiomech.2012.04.003.
13. Bisschop, A.; et al. 2013. Effects of repetitive movement on range of motion and stiffness around the neutral orientation of the human lumbar spine, J. Biomech. 46(1): 187-191. https://doi.org/10.1016/j.jbiomech.2012.10.014.

14. Goel, V. K.; Panjabi, M. M.; Patwardhan, A. G.; Dooris, A. P.; Serhan, H.; American Society for Testing Materials. 2006. Test protocols for evaluation of spinal implants, J. Bone Jt. Surg. 88(2): 103-109. https://doi.org/10.2106/JBJS.E.01363.

15. Wilke, H.-J.; Schmidt, H.; Werner, K.; Schmölz, W.; Drumm, J. 2006. Biomechanical evaluation of a new total posterior-element replacement system, Spine (Phila. Pa. 1976). 31(24): 2790-6; discussion 2797. https://doi.org/10.1097/01.brs.0000245872.45554.c0.

16. Delank, K. S. et al. 2010. How does spinal canal decompression and dorsal stabilization affect segmental mobility ? A biomechanical study, Arch. Orthop. Trauma Surg. 130(2): 285-292.

https://doi.org/10.1007/s00402-009-1002-x.

17. Sudo, H.; Oda, I.; Abumi, K.; Ito, M.; Kotani, Y.; Minami, A. 2006. Biomechanical study on the effect of five different lumbar reconstruction techniques on adjacent-level intradiscal pressure and lamina strain, J. Neurosurg. Spine 5(2): 150-155. https://doi.org/10.3171/spi.2006.5.2.150.

18. Karakaşli, A.; Çeçen, B.; Erduran, M.; Taylan, O.; Hapa, O.; Havitcioglu, H. 2014. Rigid fixation of the lumbar spine alters the motion and mechanical stability at the adjacent segment level, Eklem Hast. ve Cerrahisi 25(1): 42-46.

https://dx.doi.org/10.5606/ehc.2014.09.

G. Lukšys, K. Daunoravičienė, J. Griškevičius, M. Rimaitis, R. Stonkus, G. Terbetas

\section{EXPERIMENTAL STUDY ON SPINE SEGMENT FIXATION TECHNIQUE}

S u m m a r y

The paper presents a study on instrumented evaluation of the single spinal segment fixation techniques. In vitro tests have been completed with 6 porcine spinal samples. Two different methods of rigidly fixed segment of the lumbar spine were tested and compared with control group/unfixed spinal units (CO). One fixation technique was obtained using screws and straight rods (FSR), another - screws and bent rods simulating the anatomy of the spine (FBR). Experimental data contains deformation data under experimental test loading limitations. Obtained results showed no significant difference between fixation techniques FSR and FBR in any case of loading parameters. However, results indicated significant differences under flexion tests after rigid fixation of the spine. Due to these results, we can presume that flexion movement is the most hazardous for developing adjacent segment disease.

Keywords: spine, adjacent segment degeneration, transpedicular fixation, loading, deformation.

Received October 09, 2017

Accepted April 18, 2018 